\title{
Jet Impingement Heat Transfer on Pinned Surfaces Using a Transient Liquid Crystal Technique
}

GM S. AZAD*, YIZHE HUANG, and JE-CHIN HAN

Turbine Heat Transfer Laboratory, Department of Mechanical Engineering, Texas A and M University, College Station, TX 77843-3123, USA

\begin{abstract}
Detailed heat transfer measurements are done using a transient liquid crystal technique for an array of in-line air jets (four rows with each row having twelve jet holes) impinging orthogonally on a pinned target surface with three different spent-air crossflow orientations. Measurements are done at four jet Reynolds numbers ranging from 4850 to 18300. Pin of $0.635 \mathrm{~cm}$ in diameter (equal to the jet diameter) and $0.3175 \mathrm{~cm}$ in height are inserted on the target surfaces in two different patterns $(23 \times 9=207$ pin and $11 \times 5=55$ pin). The results show that jet Reynolds number has a strong effect on local heat transfer coefficient. The local and averaged heat transfer coefficient increases with an increase in jet Reynolds number. The crossflow direction also influences the local heat transfer coefficient. A pinned surface may produce a higher or lower heat transfer coefficient than a smooth surface, depending on the spent-air crossflow direction. The pinned surface results are comparable with the existing rough surface data.
\end{abstract}

Keywords: Jet impingement; Pinned surface; Enhanced heat transfer; Cooling; Crossflow effect

Jet impingement heat transfer is an established method of cooling, heating, or drying surfaces in a wide variety of process and thermal control applications. Examples include cooling of gas turbine airfoils and electronic equipment, drying of paper and textiles, annealing of metals, and glass tempering operations. The mid-chord region of a gas turbine blade interior of an advanced gas turbine engine that operates at a high gas temperature $\left(1300-1500^{\circ} \mathrm{C}\right)$ is also cooled by a two-dimensional array

Received 29 June 2000; in final form 30 June 2000.

This work is supported by The Texas Higher Education Coordinating Board-Advanced Technology Program (Grant \#999903-165).

*Corresponding author. of impinging jets. Thus, researchers investigate heat transfer behavior and the effect of various parameters for a variety of impinging jets that closely simulates a gas turbine airfoil internal cooling and combustion liner cooling applications.

The present literature contains many experimental studies on heat transfer behavior of impinging jets. These studies investigate the effect of various geometrical parameters, flow parameters, and spent air crossflow direction. Most of these studies deal with smooth surfaces; however, there are a few studies available on rough surfaces. Kercher and Tabakoff (1970) investigated the effect of jet diameter, jet spacing, and jet-to-surface distance for a round air-jet impinged on a flat surface. Florschuetz et al. (1980) studied the effect of jet spacing, jet-to-surface distance, and crossflow for a two-dimensional array of circular air jets impinging on a flat surface. They also presented a correlation for inline and staggered hole pattern, including the effects of geometric parameters: Streamwise hole spacing, spanwise hole spacing, and channel height to jet diameter ratio for one crossflow direction. Several studies (Chance, 1974; Florschuetz et al., 1981; Gardon \& Akfirat, 1965) presented findings relating to the parametric effects of geometry, crossflow, turbulence, etc., on jet impingement heat transfer on flat surfaces. Goldstein et al. (1986) studied jet impingement heat transfer from a single circular air jet on a heated flat plate. Downs and James (1987) presented a comprehensive literature survey of jet impingement studies before 1987.

Chupp et al. (1969) evaluated the internal heat transfer coefficient for impingement cooling on the leading edge of a turbine blade. Bunker and Metzger (1990), and Metzger and Bunker (1990) also studied impingement cooling with and without film coolant extraction on the leading edge of a turbine airfoil. Van Treuren et al. (1994) studied detailed heat transfer distribution under impinging jets. Huang et al. (1998) studied detailed heat transfer distribution on a smooth surface with different spent-air crossflow orientations. All of these studies observed an increase in 
heat transfer with jet impingement, and presented the effects of various geometrical and flow parameters on jet impingement heat transfer. Most of the data reported impinging jet heat transfer based on smooth surfaces. However, jet impingement heat transfer on rough surfaces is important in many applications, including gas turbine blades. The surfaces may become rough from the manufacturing process, a long service time, or roughness may be imposed intentionally to increase heat transfer performance.

Haiping et al. (1997) studied jet impingement heat transfer from a rib-roughened surface in the presence of an initial crossflow. They investigated the effect of the relative position of the jet hole to the ribs. They concluded that higher heat transfer values are obtained with jets impinging midway between the ribs compared with other locations. Chakroun et al. (1997) studied jet impingement heat transfer on both smooth and rough surfaces. They investigated the roughness effect on impingement heat transfer. The roughness was composed of cubes of $1 \mathrm{~mm}$ dimension distributed uniformly along the plate. They did not present a detailed distribution, and the effect of different spent-air crossflow orientation was not considered. Trabold and Obot (1987) studied impingement heat transfer on ribbed walls with different crossflow schemes. They measured the effect of geometrical and flow parameters on the heat transfer coefficient. They observed a small reduction in heat transfer coefficients in smaller $X / d$ locations, but higher heat transfer coefficients in larger $X / d$ locations for unidirectional crossflow scheme. They concluded that roughness elements (ribs) can compensate for the degradation in heat transfer usually associated with impingement on smooth surfaces. Gau and Lee (1992) studied flow structure and heat transfer along ribbed walls impinging from a single slot air jet. They investigated the effect of rib heights, rib pitch-to-height ratio, slot width-to-rib height ratio, and nozzle to target wall distance. They concluded that heat transfer on ribbed surfaces are enhanced over a smooth surface. Azad et al. (2000) studied detailed heat transfer over a dimpled surface with different crossflow orientations.

The present study will fulfill the need for additional heat transfer data on a pinned target surface with three different spent-air crossflow orientations. A pinned surface with a discontinuous roughness element (pin) may behave differently than a ribbed surface under an impinging jet. Because a rib acts as a resistance to the crossflow, it significantly disturbs the crossflow velocity. However, pin may agitate the crossflow, and produce different heat transfer coefficient. Detailed heat transfer behavior on such a pinned surface with different crossflow orientations under impinging jet is unknown in the present literature. Considering this, we have done detailed heat transfer coefficient measurements using a transient liquid crystal technique on different pinned (rough) surfaces under an array of impinging in-line jets for three different spent-air crossflow orientations. Two different pin array arrangements (many pin and less pin) on the target surface are studied. In the many-pin case, the target surface has nine rows with each row having twenty three pin $(9 \times 23=207)$. Similarly, in the less-pin case, the target surface has five rows with each row having eleven pin $(5 \times 11=55)$. Detailed heat transfer coefficient distribution data is collected for four different Reynolds numbers ranging from 4850 to 18300 . The data for the less pin case are presented only for $R e=9550$. The detailed heat transfer coefficient distribution results are presented and compared with the existing data.

\section{EXPERIMENTAL SETUP}

The experimental setup consists of a computerized data acquisition system, an electric heater, an orifice plate, a diverter valve, a plenum, and the impingement test section itself. Figure 1 shows the entire setup. The computerized data acquisition system consists of an RGB CCD camera, a computer with a frame grabber board, and a video monitor. The camera focuses on the liquid crystal-coated test surface and catches the color signals during the thermal transient test. The camera splits the color signal into red, green, and blue and passes the signals to the frame grabber board in the computer. The frame grabber board is programmed to analyze the color change using an image processing software. The video monitor works as a reference to adjust the camera focus and the threshold intensity correction for lighting. The software analyzes the picture frame by frame for a color change. The analysis records the time of transition of the liquid crystal color change from colorless to the onset of green during the transient test. The high resolution of the technique provides detailed distribution data at each point on the surface, which cannot be achieved by multiple thermocouples.

The orifice plate measures the airflow rate. The in-line air heater controls the required airflow rate and heats up the air to a preset temperature. The three-way ball diverter valve routes the air away from the test rig when no test is in progress. A strip chart recorder measures the main stream flow temperature from a thermocouple during the transient test. The test section consists of two compartments joined by a jet plate having an array of jet-holes of diameter $0.635 \mathrm{~cm}$. The top compartment is a pressure chamber, while the bottom compartment is the impingement channel. The plenum is a $91.44 \mathrm{~cm}$ long chamber through which the flow develops before entering to the pressure chamber. The jet plate thickness is equal to the jet hole diameter. The plate has four rows of holes, each row has twelve holes through the length of the plate. The jet-to-jet spacing is four times the hole diameter. The length of the test section is 


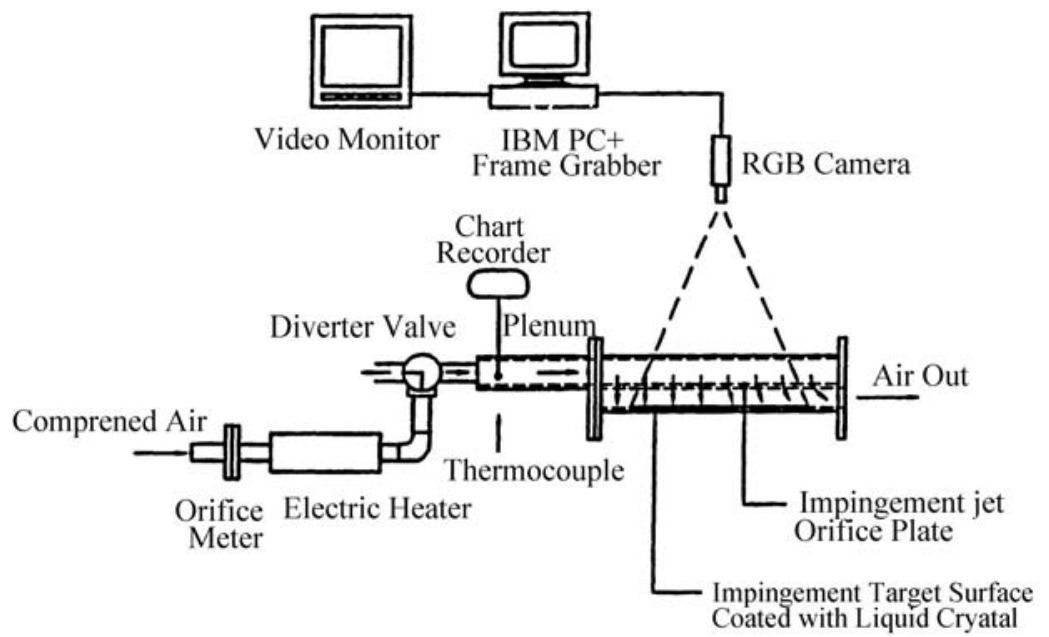

FIGURE 1 Schematic of the experimental setup.

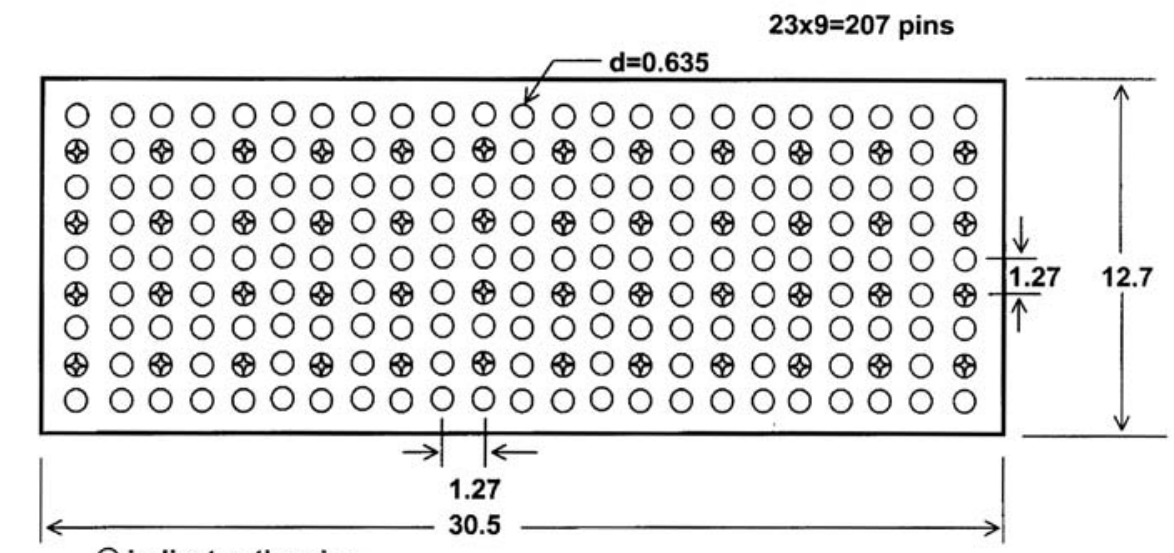

O indicates the pins

\& indicates the corresponding jet hole location

** All dimensions are in $\mathrm{cm}$
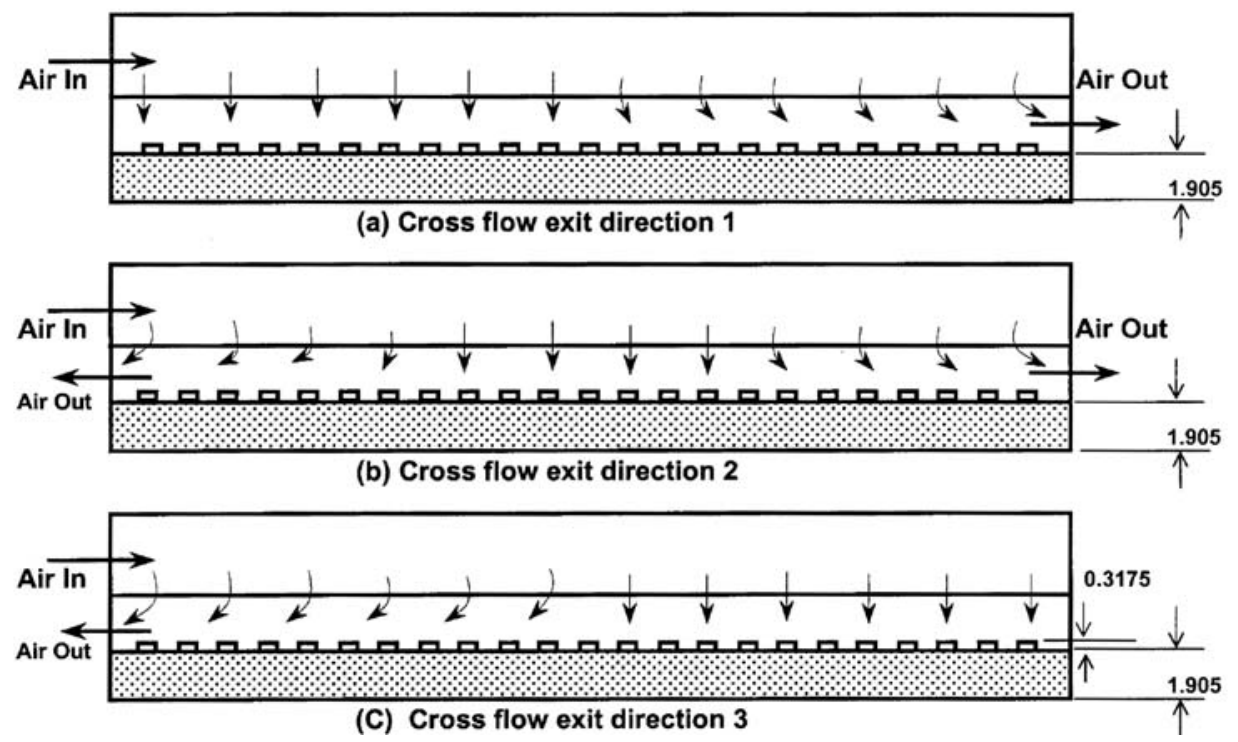

FIGURE 2 Impingement target surface with different exit flow direction (many pin case). 
$30.48 \mathrm{~cm}$. The inlet pressure chamber has a cross sectional area of $12.7 \mathrm{~cm} \times 2.54 \mathrm{~cm}$, and the impingement channel has a cross sectional area of $12.7 \mathrm{~cm} \times 1.905 \mathrm{~cm}$. The distance between the jet plate and the impingement target surface is three times the jet hole diameter. Since the study focuses on a pinned target surface, a jet plate with a typical geometry is selected. The target surface has a constant cross section of $30.48 \mathrm{~cm} \times 12.7 \mathrm{~cm}$. Pins of $0.635 \mathrm{~cm}$ in diameter (equal to the jet diameter) are inserted in different patterns on the target surfaces. In one case (many-pin case) nine rows of pin with each row having twenty-three pin $(23 \times 9=207)$, are inserted on the target surface. Similarly, the other case has five rows of pin with each row having eleven pin $(11 \times 5)$, inserted on the target surface. On both cases, the pin height above the target surface after insertion is $0.3175 \mathrm{~cm}$.

The test section is made of clear acrylic material so that the camera can see through. The impingement target surface is made from black acrylic sprayed with liquid crystals on the inside surface. The pins are also black acrylic materials sprayed with liquid crystals. The black acrylic materials are selected because they have a very low thermal conductivity and act as an insulating material. This low thermal conductivity is a requirement for our transient liquid crystal test, so that we can assume a 1-D semi-infinite solid assumption to calculate the heat transfer coefficient. The heat transfer data is taken only on the top surface of the pin and the impingement target surface between the pin. No data is taken on the peripheral surface of the pin. The peripheral surface is about $33.8 \%$ and $9 \%$ of the total projected surface area for the many and less pin cases, respectively. Figure 2 shows the target surfaces with three different exit flow direction for the many pin case. The three flow directions are obtained by changing the discharge openings. The orientations provide three different crossflow effects created by the spent jets exiting out of the impingement channel. Figure 3 shows the target surface for less pin case, the jet plate, and an enlarged view of a pin on the target plate. The pin edges are kept as it is machined without chamfering.

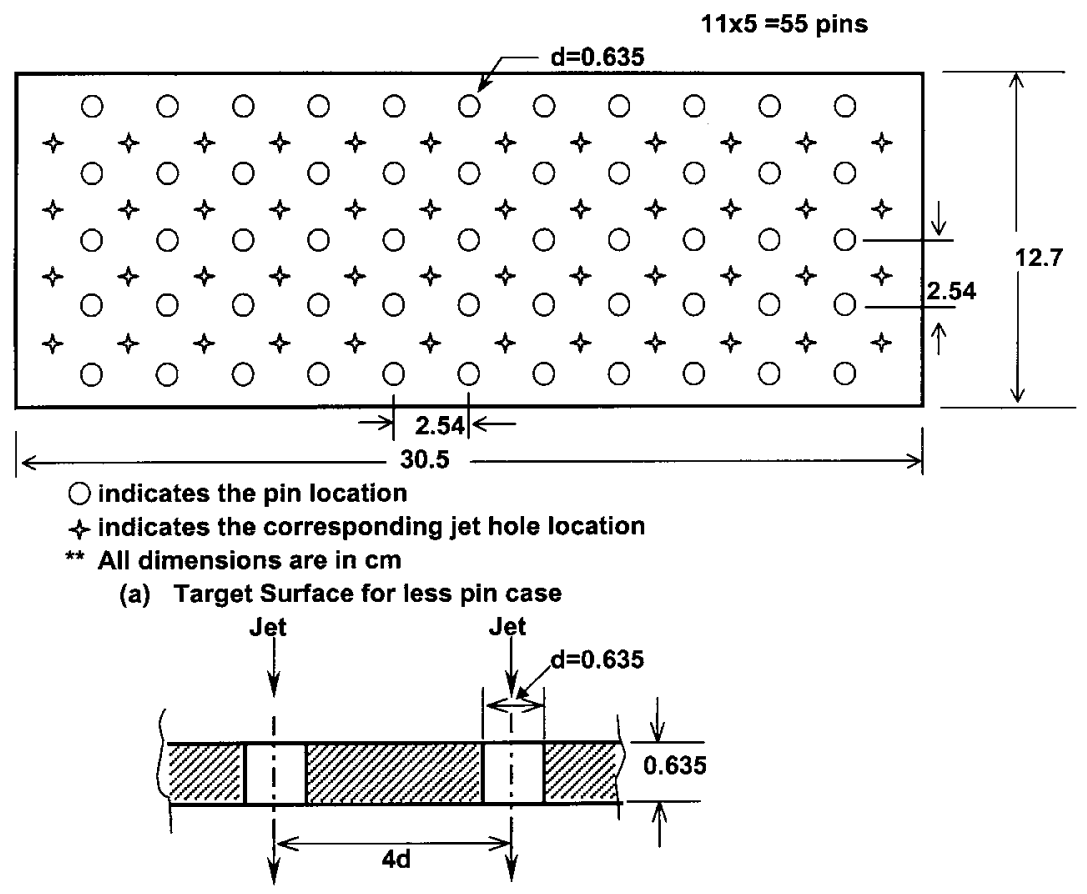

(b) Jet Plate

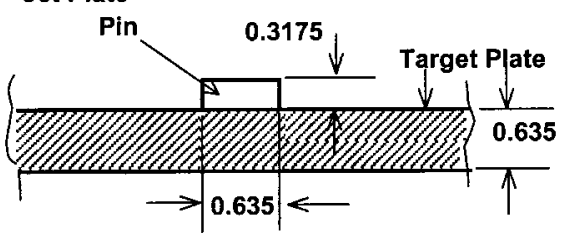

(C) Enlarged View of a Pin in the Target Plate

FIGURE 3 Target surface for less pin case, the jet plate, and a pin. 


\section{TEST PROCEDURE AND THEORY}

Liquid crystal is sprayed over the target surface, and the test section is assembled according to the desired exit flow orientation. The camera is set up and focused on the target surface. A threshold intensity method of transient liquid crystal technique is used. This method requires a background intensity correction based upon the lighting conditions on the region of interest (ROI). This ROI is our data collection region. This background light intensity correction ensures that all the points in the ROI are at intensity lower than the real color change transition. Our test surface is kept at a room temperature and heated air is introduced through the test section. Each test run is a thermal transient initiated by the sudden introduction of heated air into the test section, which results in a color change of the surface liquid crystal coating. Heated air is diverted away from the test section at the beginning of every test run so that the channel walls remain at the laboratory ambient temperature. The valve remains in the diverted position until steady flow and a preset temperature have been achieved in the diversion flow loop. The valve is then switched to route the hot air into the test section. Accurate and coordinated measurement of air temperature and the color change time is very important for reliable data. To reduce any measurement uncertainty, the automated computer data acquisition program and the chart recorder are simultaneously switched on to measure the color change (from red to the onset of green) transition time and temperature data. A typical air temperature is about $50 \mathrm{C}$, the initial temperature of the target surface is about $24 \mathrm{C}$, the liquid crystal color change (from red to the onset of green) temperature is $32.7 \mathrm{C}$, and the color change time is about $10-40$ seconds. Each test is repeated to check data repeatability. The data acquisition system transfers the data into a matrix of color change time over the entire surface. A computer program calculates the local heat transfer coefficient from the time and temperature data.

The test condition is assumed to be a one dimensional transient conduction model through a semi-infinite solid with surface convection. The following equation describes the surface temperature.

$$
\frac{T_{w}-T_{i}}{T_{m}-T_{i}}=1-\exp \left(\frac{h^{2} \alpha t}{k^{2}}\right) \operatorname{erfc}\left(\frac{h \sqrt{\alpha t}}{k}\right)
$$

where, $T_{i}(\sim 24 \mathrm{C}), \quad T_{m}(\sim 50 \mathrm{C}), t(\sim 10-40 \mathrm{sec}), T_{w}$ $(32.7 \mathrm{C}), k$, and $\alpha(k / \rho c)$ of the solid are known and $h$ is unknown. Note that the target surface is made of acrylic, which has a very low thermal conductivity $(\sim 0.18 \mathrm{~W} / \mathrm{m} \mathrm{K})$. The test duration is small enough than the time required for the temperature to penetrate the full thickness of the insulating acrylic material. The liquid crystal color-change transition occurs only at the surface, which was initially at a uniform room temperature. Thus, we can consider a semi-infinite solid assumption. This assumption is even valid near the corners of the pin except the exact corner edge. The heat transfer coefficient $h$ can be calculated from Eq. [1].

The mainstream air is heated to a preset temperature $(50 \mathrm{C})$, which makes the color change time from $10-40 \mathrm{sec}$. The chart recorder measures the gradual change of the mainstream temperature during the transient test. The mainstream temperature is measured at the inlet of the pressure channel. However, we need to know the temperature of the air immediately before impingement. The mainstream temperature cannot be represented as a single step change. Since the mainstream temperature depends on time, the solution represented by Eq. [1] must include the gradual change of the temperature. The time history of the mainstream air temperature is reproduced as a series of step function and then using Duhamel's superposition theorem, the solution in Eq. [1] is represented as:

$$
\begin{aligned}
T_{w}-T_{i}=\sum_{j=1}^{N}[1 & -\exp \left(\frac{h^{2} \alpha\left(t-\tau_{j}\right)}{k^{2}}\right) \\
& \left.\times \operatorname{erfc}\left(\frac{h \sqrt{\alpha\left(t-\tau_{j}\right)}}{k}\right)\right]\left[\Delta T_{m j}\right]
\end{aligned}
$$

where $\Delta T_{m j}$ and $\tau_{j}$ are the temperature and time step changes from the chart recorder output. Equation [2] is solved to obtain the local heat transfer coefficient at every point on the measured region $(250 \times 100$ points $)$. The uncertainty in the Nusselt number, estimated by the method of Kline and McClintock (1953), is $\pm 5.9 \%$.

\section{RESULTS AND DISCUSSION}

Jet impingement heat transfer depends on several flow and geometrical parameters, including $R e$, $\mathrm{Pr}$, jet spacing to diameter ratio $(X / d, Y / d)$, jet plate to target plate distance to diameter ratio $(Z / d)$, the jet inclination angle $(\alpha)$. The target surface condition and the flow exit orientation also have a significant effect on impingement heat transfer. This work studies the effect of the target surface condition with a pinned surface for different spent-air crossflow orientations on local heat transfer from impinging air jet. The heat transfer data are collected and presented for Reynolds numbers ranging from 4850 to 18300 . The results are presented for different crossflow orientations. Detailed local heat transfer coefficients and span-averaged Nusselt number distributions are presented and the results are compared with existing data. 


\section{Detailed Local Heat Transfer Coefficients}

Figures 4-6 show detailed local Nusselt number distributions for three crossflow orientations. The Nusselt number distributions are presented as a function of nondimensional location $X / d$ and $Y / d$. The results are presented from $X / d=3.5$ to $X / d=44.5$ in the streamwise direction over the entire span. Results shown in the detailed distribution correspond to the ten central jet hole locations out of the twelve jet holes of the plate. Results corresponding to the two end holes are not shown in the distributions. The jet mass flow distribution pattern is helpful to interpret the heat transfer results. In an earlier related study by Huang et al. (1998), the pressure distribution and the corresponding jet mass flow were measured for the same flow condition with a smooth target surface instead of a pinned surface. The results show that the jet mass flow rate jumps from first hole location to the second hole location, and then slightly increases toward the higher $X / d$ for crossflow orientation 1 , while it slightly increases from first jet hole toward the higher $X / d$ for orientation 2. However, it remains almost constant for orientation 3 . The maximum variation of jet mass flow rate occurs for orientation 1 , and the variation is about $\pm 6 \%$ from its average value. The same jet plate and the pressure chamber are used for this pinned surface. We expect an approximately similar jet flow distribution patterns in this pinned case.

Figure 4 presents the detailed distributions for flow orientation 1. In this orientation, the flow enters the pressure chamber at one end $(X / d=0)$ and exits the impingement channel on the other end $(X / d=48)$. The flow enters and exits in the same direction. The result show that the local heat transfer coefficient increases with an increase in the jet Reynolds number. The local heat transfer coefficient very slightly increases with an increase in $X / d$. The top surface of the pin and the surrounding area of several pin show a higher heat transfer coefficient. For many pin case, the pin, which are directly under the jets, have higher heat transfer coefficients than the neighboring pin. The surrounding area of these pin also show higher heat transfer coefficient, because the jet may not impinge only on the top surface of the pin, but splits into the surrounding area, resulting in a higher heat transfer coefficient. Similarly, for less pin case, the jet-impinged area shows a higher heat transfer coefficient. The pin acts as a flow turbulator and creates disturbance to the crossflow, which prevents any boundary layer development near the target surface. The amount of spent air crossflow increases with increasing $X / d$. Due to a higher mass flow rate, the crossflow velocity also increases with increasing $X / d$. While passing over the pin, the shearing of the crossflow creates turbulence, which results in a higher heat transfer coefficient over the top surface of the pin. Similarly, while passing across the cylindrical pin, horse-shoe vortices and

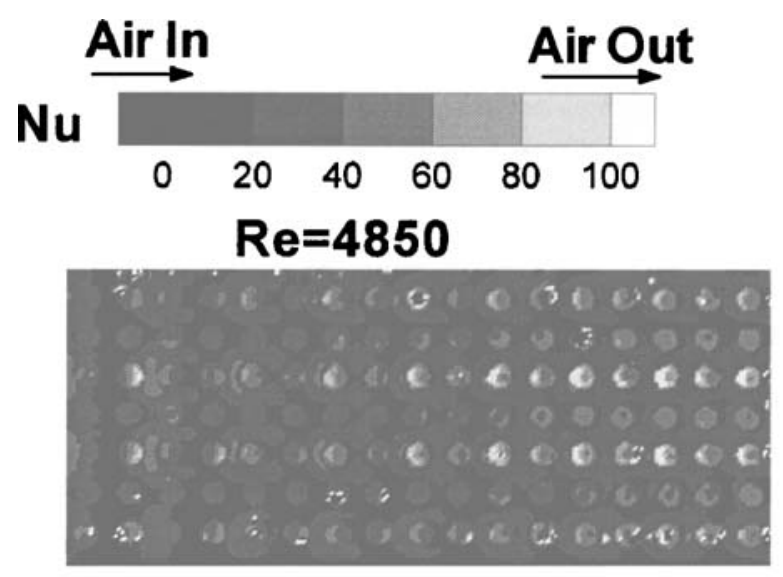

\section{$\mathrm{Re}=9550$}

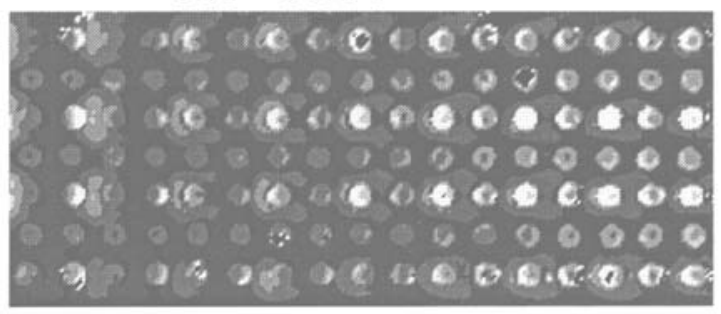

\section{$\mathrm{Re}=\mathbf{1 2 8 0 0}$}

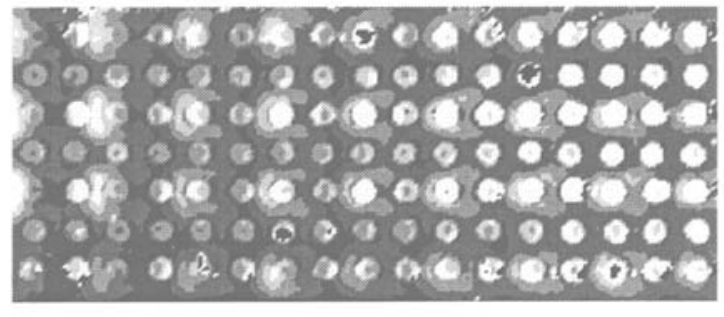

$\mathrm{Re}=\mathbf{1 8 3 0 0}$

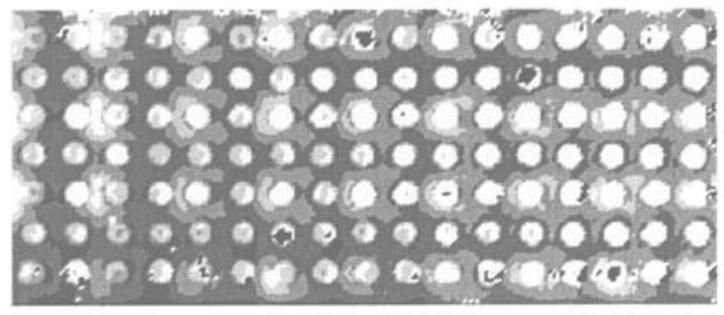

$\mathrm{Re}=9550$; less pin case

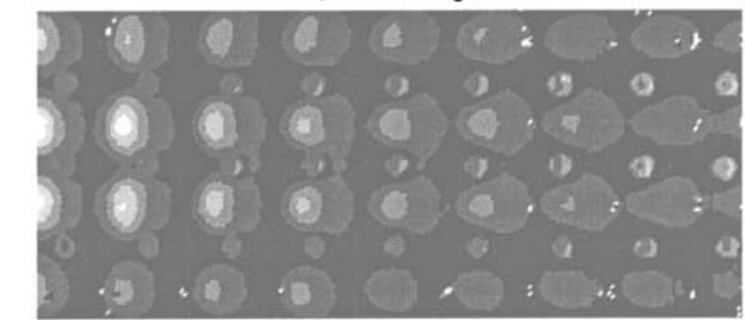

$\mathrm{X} / \mathrm{d}=\mathbf{3 . 5}$

$\mathrm{X} / \mathrm{d}=\mathbf{4 4 . 5}$

FIGURE 4 Detailed Nusselt number distributions for orientation 1. 

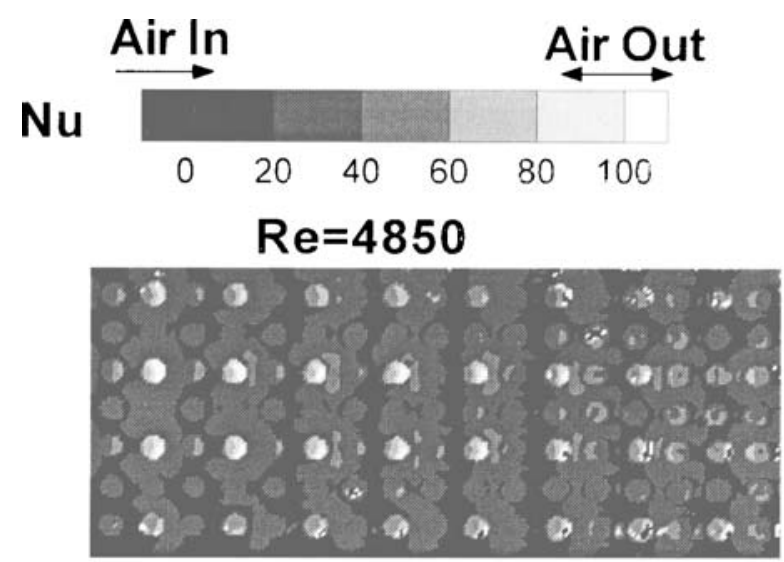

\section{$\mathrm{Re}=9550$}
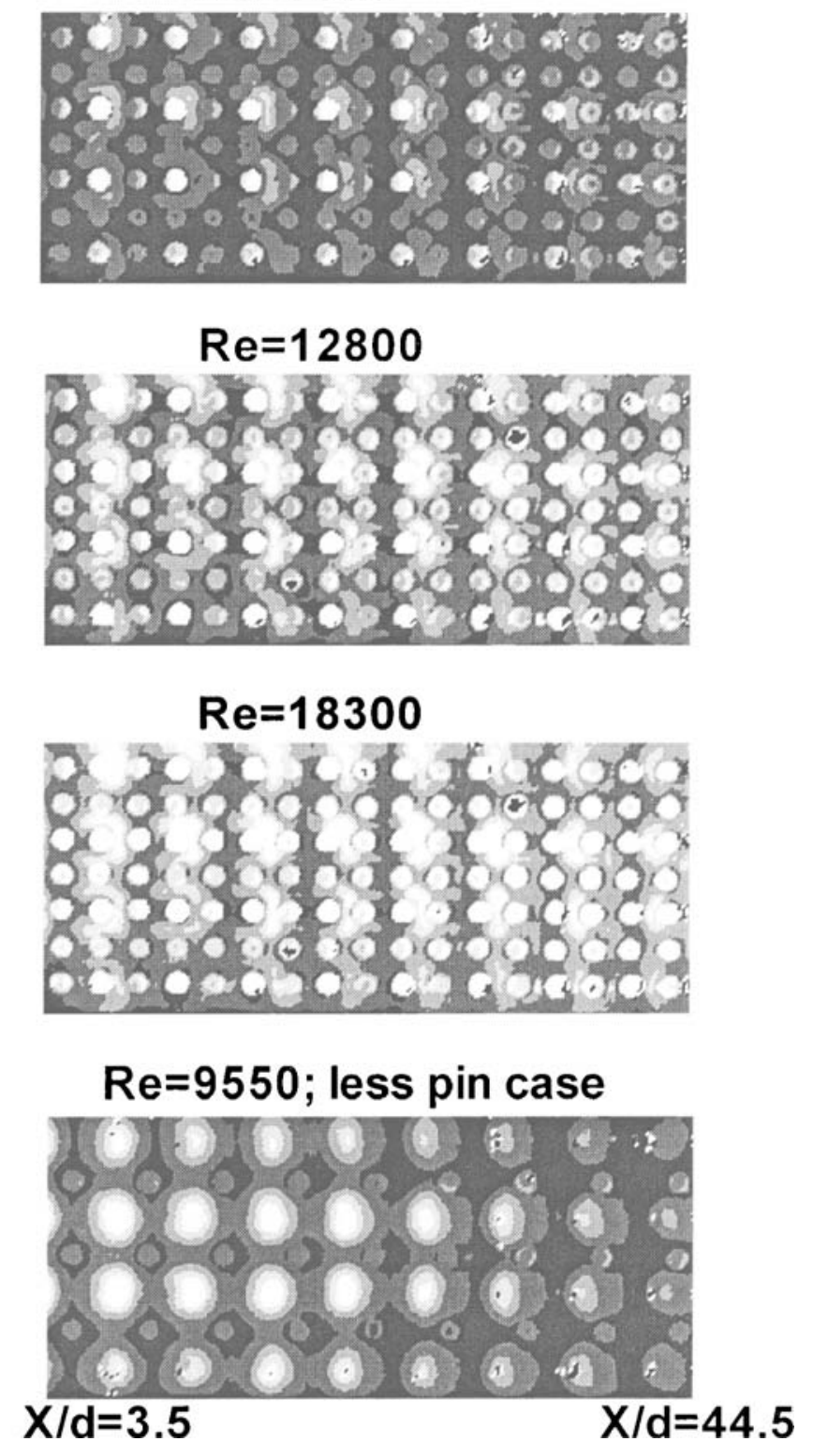

FIGURE 5 Detailed Nusselt number distributions for orientation 2.
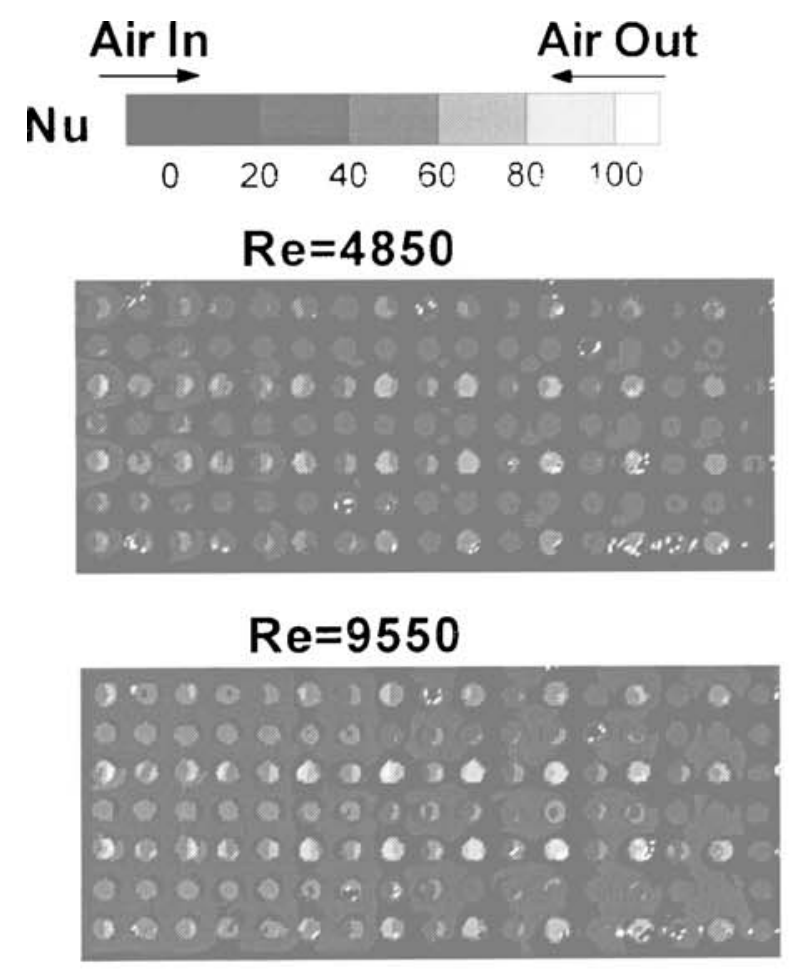

\section{$\mathrm{Re}=12800$}

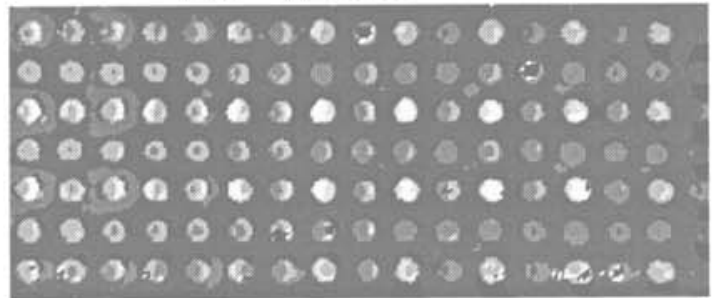

\section{$\mathrm{Re}=18300$}

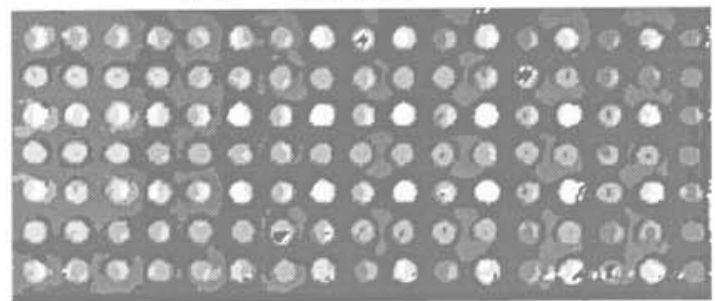

$\mathrm{Re}=9550$; less pin case

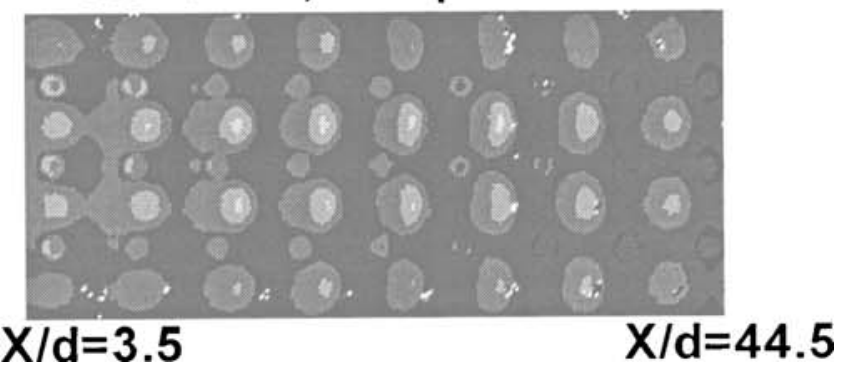

FIGURE 6 Detailed Nusselt number distributions for orientation 3 . 
wakes are generated, which enhances heat transfer on the target surface.

Figure 5 shows the detailed distributions for flow orientation 2. In this orientation, the flow enters the pressure chamber at one end $(X / d=0)$ and exits at both ends. The heat transfer coefficient increases with an increase in jet Reynolds number. The heat transfer coefficient patterns are almost uniform throughout the target surface. However, a higher local heat transfer coefficient is observed on the location that is directly under the impinging jets.

Figure 6 shows the detailed distributions for flow orientation 3. In this orientation, the flow exits in the opposite direction of the flow entrance. This means that the flow exits and enters at $(X / d=0)$. The local heat transfer coefficients are relatively small compared with the other two flow orientations. In this orientation, most of the spent air exits easily through the exit end (see Figure 2 (c)) and does not posses a longer distance of crossflow. At higher, $X / d$, the spent air crossflow is minimum, and the amount of spent air crossflow increases toward lower $X / d$. Due to this higher mass flow rate, the crossflow velocity also increases with decreasing $X / d$. Thus, the pin effect (more turbulence of the crossflow, generation of wakes and vortices) is prominent toward lower $X / d$, which results in a slightly higher heat transfer coefficient in the flow exit direction similar to orientation 1 .

In all the three flow orientations, increased jet Reynolds numbers increase the local heat transfer coefficient throughout the target surface. The higher jet velocity also increases the crossflow velocity. When flowing across the pin, due to higher crossflow velocity, more wakes and vortices are generated by the cylindrical pin, which destroys the boundary layer near the target surface, and the higher turbulence over the pin surface enhances the heat transfer.

\section{Span-averaged Nusselt Number Distributions}

Figure 7 shows the Reynolds number effect on spanaveraged Nusselt number distributions with three exit flow orientations for the many pin case. In every orientation, the Nusselt numbers increase with an increase in jet Reynolds number. The Nusselt number slightly increases toward the exit direction in flow orientation 1 and 3. However, the Nusselt number is almost uniform over the entire target surface in orientation 2, where the flow exits in both directions. The highest points of Nusselt number values in these figures correspond to the jet impingement locations. However, a fluctuating secondary peak is observed at some points near the highest peak points. These may be the points, where the splitted jet impinges on the target surface between the pin or the jet after impinging on the pin may split and impinges on the bottom surface. In many pin case, the jet impinges on the top surface of the pin. However, due to crossflow direction, the jet may bend and a portion of the jet may impinges on the surface between the pin. Even without bending, the jet may split upon impingement on the pin top surface, and may impinge again on the bottom target surface. Thus, increasing the heat transfer coefficient at that location. However, the secondary peak is not observed in the less pin case, because the jet directly impinges on the bottom surface between the pin. The arrows at the bottom of each figure indicate the impinging jet hole locations.

Figure 8 shows the flow orientation effect on spanaveraged Nusselt numbers for $R e=9500$. Flow orientations 1 and 2 provide higher heat transfer coefficients compared to orientation 3 for both cases (many pin and less pin). In orientation 3, most of the spent air exit easily through the exit end and do not posses a longer distance of crossflow. As the crossflow exit direction is opposite to the flow direction in the pressure chamber, the overall flow field in the impingement channel may be retarded, which results in a lower heat transfer coefficient. For many pin case, the heat transfer coefficient increases toward the exit flow direction in orientation 1 and 3 , and almost uniform throughout the target surface in orientation 2 . This happens because of the pinned surface. The pin creates disturbances to the crossflow and prevents any boundary layer development near the target surface. Wakes and horseshoe vortices are generated as the crossflow pass across the cylindrical pin. The shearing of the crossflow over the top surface of the pin also creates turbulence. Thus, the higher the crossflow velocity, the more disturbances, and the higher the heat transfer coefficient. However, for less pin case, the pin effect is negligible. The jets impinge on the smooth surface between pin. The target surface does not have many pins to create large enough wakes or vortices, and turbulence to have a significant effect on heat transfer. Thus, the heat transfer coefficient decreases toward the exit direction in all three orientations, as happened for a smooth surface case as shown by Huang et al. (1998).

\section{Comparison with Existing Results}

Previous jet impingement studies considered the effects of several geometrical and flow parameters on smooth surfaces. Several correlations are available in the existing literature; however, only a few jet impingement studies are available on rough surfaces. The results are compared with some smooth and rough surface data that are available in the existing literature. Detailed heat transfer coefficient distributions from this study are averaged over the entire target plate to get a single value for each Reynolds number and each orientation. Note that the heat transfer data is 

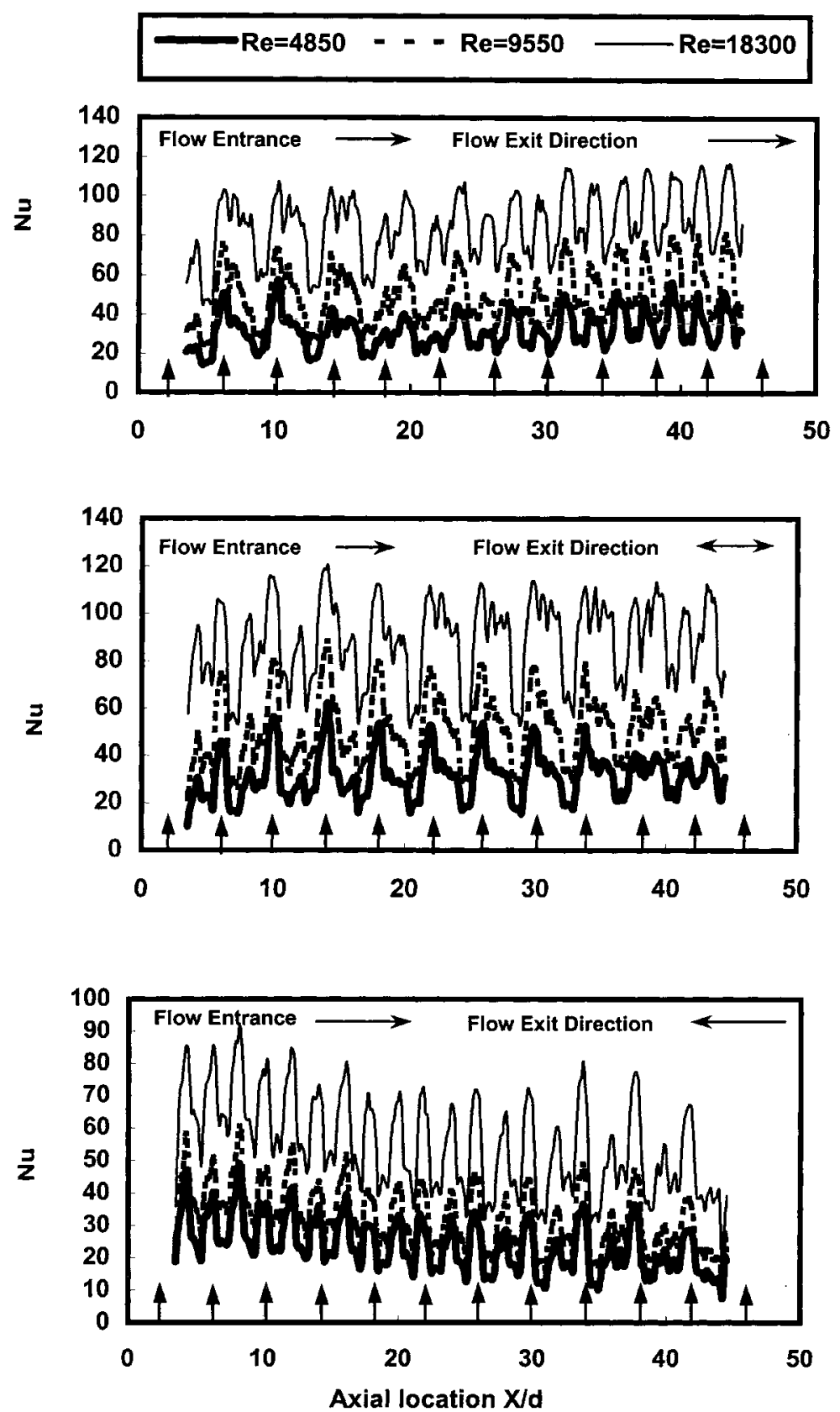

FIGURE 7 Effect of $R e$ on span-averaged $N u$ for different exit flow direction (many pin case).

collected only on the top surface of the pin and the smooth target surface between pins. The data is not taken from the pin-increased area (peripheral surface) of the pin, which is about $33.8 \%$ and $9 \%$ of the total projected surface area for the many pin and the less pin cases, respectively. This increased heat transfer area will further increase the heat transfer rate from the pinned wall; however, this additional amount of heat transfer is not included in this study. The averaged Nusselt numbers for each orientation are plotted as a function of Reynolds number to compare with the existing data as shown in Figures 9 and 10. The present data for orientations 1 and 2 correlate with the Reynolds number dependence as $N u=0.041 R e^{0.78}$. Similarly, the present data for orientation 3 correlates with the Reynolds number dependence as $N u=0.11 R e^{0.63}$.

Figure 9 compares the same three spent air crossflow orientations in this study on pinned surfaces and the study on a smooth surface by Huang et al. (1998). The correlation 

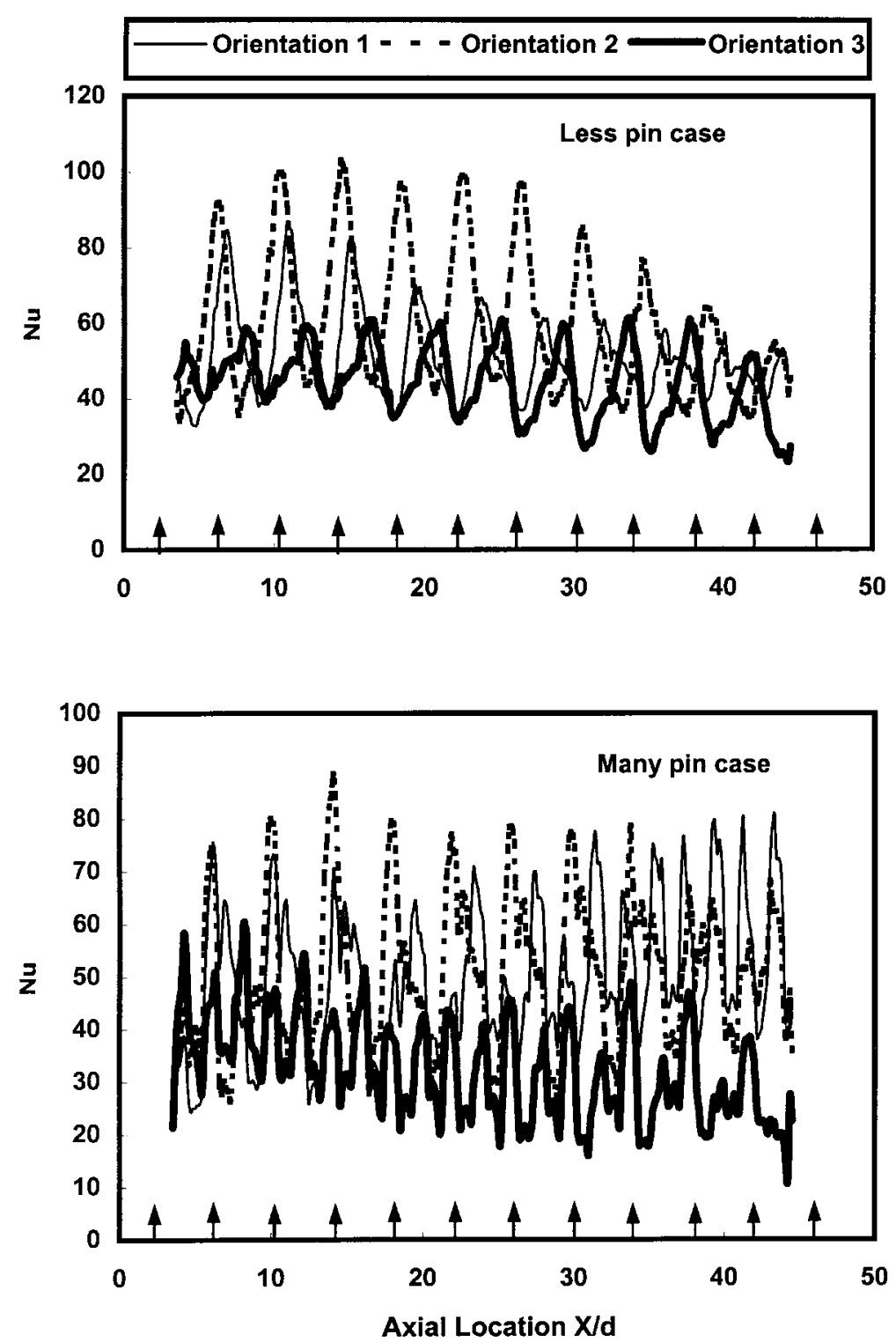

FIGURE 8 Span averaged $N u$ as a function of exit flow direction $(R e=9550)$.

developed by Kercher and Tabakoff (1970) is also included for comparison. Huang's (1998) smooth surface result reveals that flow orientation 2 provides the highest heat transfer coefficient over the entire surface, while flow orientation 3 provides the lowest. The crossflow has a limited effect for flow orientation 2 compared to that for orientations 1 and 3 . The heat transfer coefficient for flow orientation 3 might be lower because of the exit of the impingement channel being on the same side as the inlet to the pressure chamber. Huang's (1998) smooth surface data for orientation 1, and Kercher and Tabakoff's (1970) correlated data are about the same. The crossflow effect in Kercher and Tabakoffs (1970) study is similar to that for flow orientation 1 in Huang's (1998) study.
This study uses similar geometrical parameters $(X / d, Y / d$, $Z / d$ ), and spent air crossflow orientations as in Huang's study (1998), except the pinned target surface instead of a smooth one. The pinned surface Nusselt numbers for orientations 1 and 2 are about the same but higher than orientation 3. In orientation 3, most of the spent air exit easily and do not posses a longer distance of crossflow as the exit end being on the same side of the flow entrance in the pressure chamber. These results when compared with Huang's (1998) smooth surface data reveals that, the Nusselt numbers for the pinned surface (many pin case) are about $30 \%$ higher than the smooth surface for orientation 1 , while the Nusselt numbers for both cases are about the same for orientation 2. However, for orientation 3, the Nusselt 


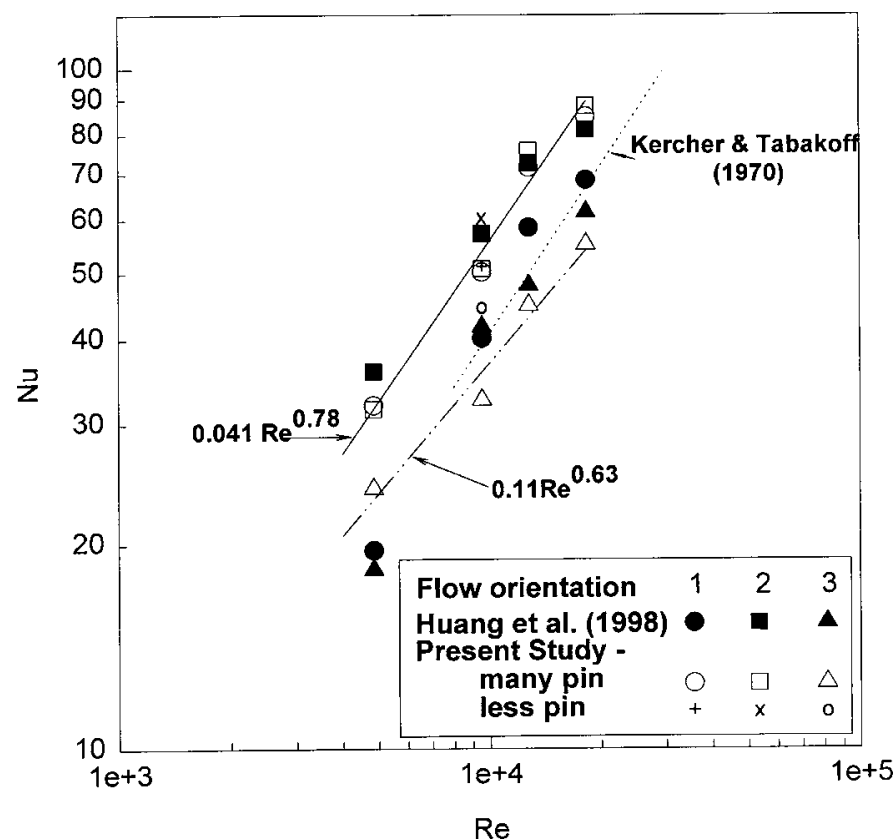

FIGURE 9 Comparison of averaged $N u$ with existing smooth surface data.

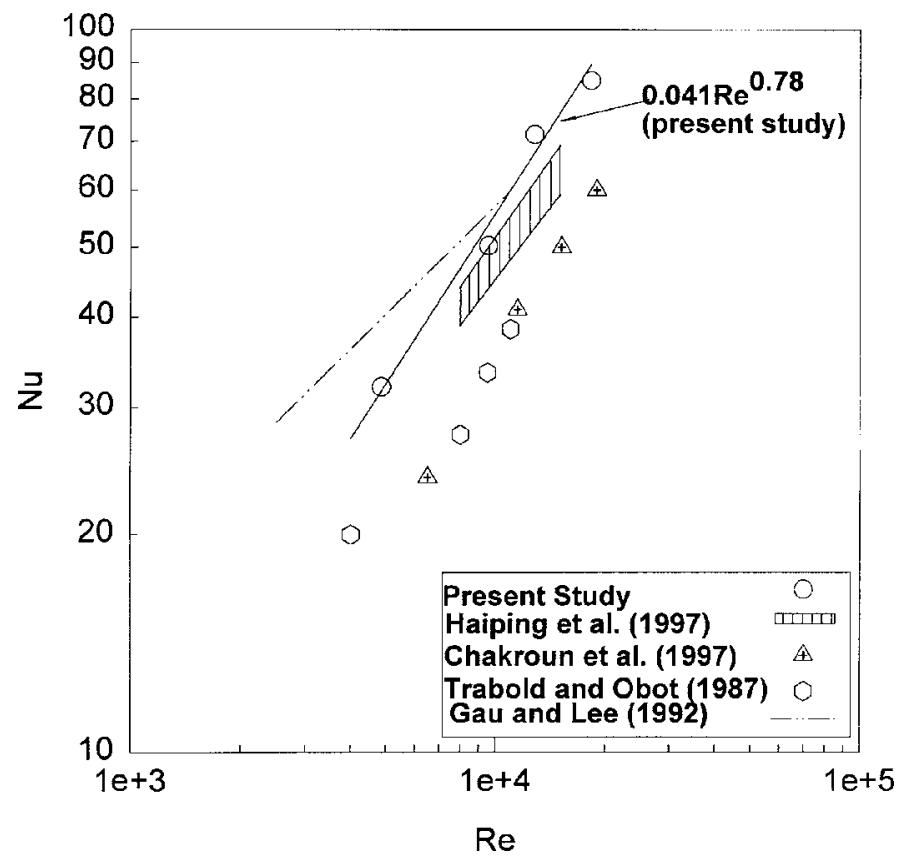

FIGURE 10 Comparison of averaged $\mathrm{Nu}$ with existing rough surface data.

numbers for the pinned surface (many pin case) are lower than the smooth surface except at low Reynolds numbers. For less pin case, the Nusselt numbers are obtained at only one Reynolds number $(R e=9550)$. For less pin case, the Nusselt number in orientation 1 is about same as the many pin case but higher than the smooth surface, while the
Nusselt numbers for orientation 2 and 3 are higher than many pin case, and about same as the smooth surface. The pin acts as flow turbulator. Wakes and vortices are generated as the crossflow passes across the cylindrical pin. It prevents any boundary layer formation near the target surface. Similarly, shearing of the crossflow over the top surface of the pin creates turbulence. Thus, the pin enhances heat transfer, as happened in orientation 1 for the many pin and the less pin case. In orientation 2, the crossflow exits in both ends. Thus, the amount of crossflow passing over the pin reduces, and the effect of the pin is not prominent. In orientation 3 , the many pin may retard the crossflow velocity (by blocking the flow) resulting in a decrease in Nusselt number than the smooth surface case, while in the less pin case, the Nusselt number value is close to the smooth surface case. The Nusselt numbers for flow orientations 1 and 2 are higher than the correlated results of Kercher and Tabakoff (1970). This result demonstrates that crossflow has a stronger effect on the heat transfer coefficient, and a pinned surface can produce higher Nusselt numbers than a smooth surface depending on the crossflow orientation.

Figure 10 compares the results for the many pin case for flow orientation 1 with some existing impingement heat transfer data on rough surfaces (Haiping et al., 1997; Chakroun et al., 1997; Trabold \& Obot, 1987; Gau \& Lee, 1992). Haiping et al. (1997) studied jet impingement heat transfer on rib-roughened surfaces with an initial crossflow. They studied four different relative positions of the jet hole to the ribs. The range of Nusselt numbers for all four relative positions are compared with the present data. Chakroun et al. (1997) investigated jet impingement heat transfer on rough surfaces. The roughness was composed of $1 \mathrm{~mm}$ cubes distributed uniformly (spaced $5 \mathrm{~mm}$ apart) along the plate. Only a single air jet was impinging normally on the target surface. They varied the nozzle to plate distance. The results for the jet hole on the ribs and for $Z / d=3$ are compared with the present results to maintain similarity in the test conditions. Haiping's (1997) data ranges are lower but closer to the present data. Chakroun's (1997) data are far lower than the present data, because they used a single impinging jet. Haiping (1998) did not mention the total number of jets used in the study. The jet spots on the impinging surface (jet impinging area to total area) may be less than our present case.

Trabold and Obot (1987) studied jet impingement heat transfer on surfaces having repeated square ribs. The heat transfer data with a crossflow scheme similar to our orientation 1 is compared. The Nusselt numbers from their study are lower than our data because, the flow conditions are different from ours. They presented results for $Z / d=2$, rib pitch to height ratio $=10$, and jet spot area to open area $=0.0196$. In our study, however, the equivalent values are 3, 4, and 0.041 respectively. The jet spots have higher heat transfer coefficients, thus the more jet spots in our 
study provide higher Nusselt numbers. Gau and Lee (1992) provided a correlation of stagnation point Nusselt number. The correlated values are higher than our data at low Reynolds number, but lower at higher Reynolds number. Our data represents the spanwise averaged Nusselt number over the entire target surface. However, their correlation only represents the Nusselt numbers directly under the jets.

This study clearly demonstrates that discontinuous round pin (roughness element) may produce higher heat transfer coefficient in impingement heat transfer than usual ribs. The pattern of pin (as tested here) has little influence on the heat transfer coefficient enhancement in spent air crossflow orientation 1 . This study also provides a detailed measurement through the entire target surface, while the other studies measured at several discrete locations.

\section{CONCLUSION}

This study investigated the effect of a pinned surface on the local heat transfer coefficients for multiple jet impingement with three crossflow orientations. The local and averaged Nusselt numbers are measured. The results conclude that:

(1) Detailed measurement provides a better understanding of the jet impingement on a pinned surface. These detailed heat transfer coefficient results also provide a reference for further experimental or computational study.

(2) The jet Reynolds number has a strong effect on local heat transfer coefficient. The local and the averaged Nusselt numbers increase with an increase in the jet Reynolds number.

(3) For the pinned surface, crossflow orientation 1 and 2 provide about same heat transfer coefficient, which is higher than orientation 3 .

(4) The pinned surface provides much higher (about 30\%) heat transfer coefficient than the smooth surface case in orientation 1 , while the heat transfer coefficients in orientation 2 are about the same for both the pinned and smooth surface. In orientation 3, however, the heat transfer coefficient for pinned surface is lower than the smooth surface except at low Reynolds number.

(5) The number of pin does not produce significant difference on the averaged impingement heat transfer coefficients based on the many pin and the less pin in this study.

\section{NOMENCLATURE}

$A$ heat transfer surface area

$d$ impingement jet hole diameter $h \quad$ local convection heat transfer coefficient, $\mathrm{W} / \mathrm{m}^{2}-\mathrm{K}$

$k$ thermal conductivity of acrylic material

$k_{\text {air }}$ thermal conductivity of air

$\mathrm{Nu} \quad$ Nusselt number, $h d / k_{\text {air }}$

Pr Prandtl number

Re average jet Reynolds number, $\rho V d / \mu$

$T_{i} \quad$ initial temperature of the target surface

$T_{m}$ mainstream temperature of the flow

$T_{w}$ color change temperature of the liquid crystal, redto-green

$t$ transition time for liquid crystal color change

$V$ average jet velocity

$X$ axial distance of the impingement target surface

$Y$ spanwise distance of the impingement target surface

$Z \quad$ distance between jet plate and target plate

$\alpha \quad$ thermal diffusivity of acrylic material, and also jet inclination angle

$\mu \quad$ dynamic viscosity of air

$\tau$ time step

\section{REFERENCES}

Azad, G. S., Huang, Y., and Han, J. C. (2000) Impingement Heat Transfer on Dimpled Surfaces using a Transient Liquid Crystal Technique, AIA A Journal of Thermophysics and Heat Transfer, 14(2), 186-193.

Bunker, R. S. and Metzger, D. E. (1990) Local Heat Transfer in Internally Cooled Turbine Airfoil Leading Edge Regions: Part II - Impingement Cooling with Film Coolant Extraction, ASME Journal of Turbomachinery, 112(3), 459-466.

Chakroun, W. M., Al-fahed, S. F., and Abdel-Rehman, A. A. (1997) Heat Transfer Augmentation for Air Jet Impinged on Rough Surface, Int. Gas turbine and Aeroengine Congress and Exhibition, Orlando, Florida, ASME Paper No. 97-GT-436.

Chance, J. L. (1974) Experimental Investigation of Air Impingement Heat Transfer under an Array of Round Jets, TAPPI, 57(1), 108-112.

Chupp, R. E., Helms, H. E., McFadden, P. W., and Brown, T. R. (1969) Evaluation of Internal Heat Transfer Coefficients for Impingement Cooled Turbine Blades, Journal of Aircraft, 6(1), 203-208.

Downs, S. J. and James, E. H. (1987) Jet Impingement Heat Transfer - A Literature Survey, American Society of Automotive Engineers, ASME Paper No. 87-HT-35.

Florschuetz, L. W., Berry, R. A., and Metzger, D. E. (1980) Periodic Streamwise Variation of Heat Transfer Coefficients for Inline and Staggered Arrays of Circular Jets with Crossflow of Spent Air, ASME Journal of Heat Transfer, 102(1), 132-137.

Florschuetz, L. W., Truman, C. R., and Metzger, D. E. (1981) Streamwise Flow and Heat Transfer Distribution for Jet Impingement with Crossflow, ASME Journal of Heat Transfer, 103(2), 337-342.

Gardon, R. and Akfirat, J. C. (1965) The Role of Turbulence in Determining the Heat Transfer Characteristics of Impinging Jets, Int. Journal of Heat Mass Transfer, 8, 1261-1272.

Gau, C. and Lee, C. C. (1992) Impingement Cooling Flow Structure and Heat Transfer along Rib-Roughened Walls, Int. Journal of Heat and Mass Transfer, 35(11), 3009-3020.

Goldstein, R. J., Behbahani, A. I., and Helppelmann, K. (1986) Streamwise Distribution of the Recovery Factor and the Local Heat Transfer Coefficient to an Impinging Circular Air Jet, Int. Journal of Heat Mass Transfer, 29, 1235-1286.

Haiping, C., Dalin, Z., and Taiping, H. (1997) Impingement Heat Transfer from Rib Roughened Surface within Arrays of Circular Jet: The Effect of the Relative Position of the Jet Hole to the Ribs, Int. Gas Turbine and Aeroengine Congress and Exhibition, Orlando, Florida, ASME Paper No. 97-GT-331. 
Huang, Y., Ekkad, S. V., and Han, J. C. (1998) Detailed Heat Transfer Distributions under an Array of Orthogonal Impinging Jets, AIAA Journal of Thermophysics and Heat Transfer, 12(1), 73-79.

Kercher, D. M. and Tabakoff, W. (1970) Heat Transfer by a Square Array of Round Air Jets Impinging Perpendicular to a Flat Surface including the Effect of Spent Air, Journal of Engineering and Power, 92(1), 73-82.

Kline, S. J. and McClintock, F. A. (1953) Describing uncertainties in Single Sample Experiments, Mechanical Engineering, 75(1), 3-8.

Metzger, D. E. and Bunker, R. S. (1990) Local Heat Transfer in Internally Cooled Turbine Airfoil Leading Edge Regions: Part I - Impingement
Cooling without Film Coolant Extraction, ASME Journal of Turbomachinery, 112(3), 451-458.

Trabold, T. A. and Obot, N. T. (1987) Impingement Heat Transfer within Arrays of Circular Jets. Part II: Effects of Crossflow in the Presence of Roughness Elements, Gas Turbine Conference and Exhibition, Anaheim, California, ASME Paper No. 87-GT-200.

Van Treuren, K. W., Wang, Z., Ireland, P. T., and Jones, T. V. (1994) Detailed Measurements of Local Heat Transfer Coefficient and Adiabatic Wall Temperature Beneath an Array of Impingement Jets, ASME Journal of Turbomachinery, 116(2), 369-374. 

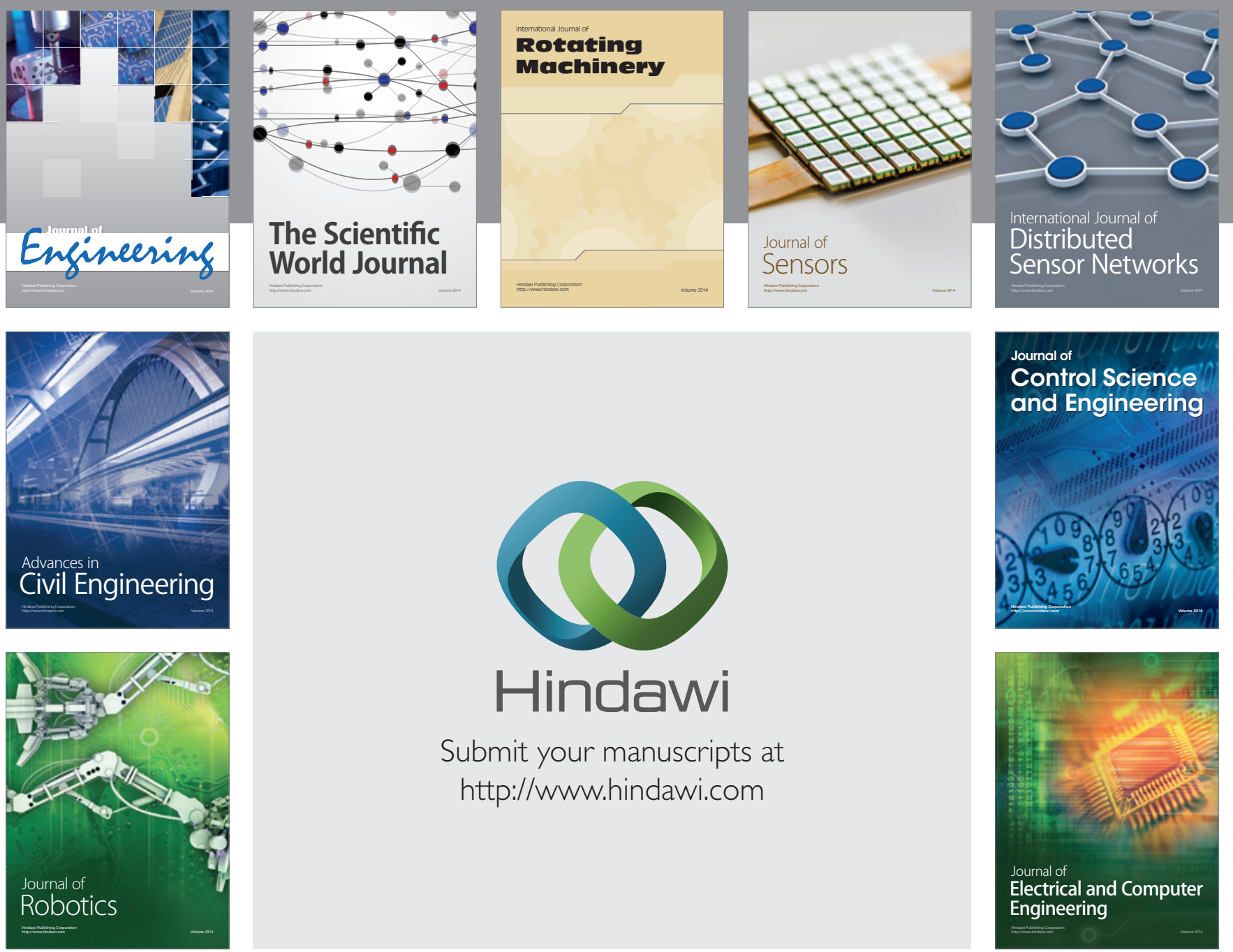

Submit your manuscripts at

http://www.hindawi.com
